\title{
Calidad del huevo expendido en los comercios tradicionales y en régimen de autoservicios
}

\section{Quality of the egg sold in traditional shops and self-services.}

Shiroma Patricia 1

\section{RESUMEN}

El objetivo del trabajo fue evaluar la calidad de los huevos expendidos en comercios tradicionales y en régimen de autoservicios del distrito de Miraflores. Se analizó un total de 248 huevos. De los cuales 124 provenían de comercios tradicionales (tiendas, mercado) y 124 huevos de comercios en régimen de autoservicio (hipermercado, supermercados). Se evaluaron características externas como la limpieza e integridad, grosor de la cascara, peso y tamaño del huevo.

Además, características internas como el diámetro y color de la yema, la consistencia de la clara, la presencia de manchas (carne o sangre) en la clara y en la yema, la frescura del huevo. En los comercios tradicionales, se comercializaban huevos por kilo, más sucios $(24,19)$ y con más de 17 días de almacenamiento. En los autoservicios, se comercializaban huevos envasados en maple (100\%), más limpios $(98,39 \%)$ y con menos días de almacenamiento ( $<12$ días). En ambos tipos de comercios, se observaron huevos con manchas de carne y / o sangre en la clara, yema o en ambas partes del huevo. Se concluyó que los comercios tradicionales comercializan huevos de menor calidad en comparación con los autoservicios.

Palabra clave: Cáscara de huevo, control de calidad, yema de huevo, clara de huevo

\section{ABSTRACT}

The objective of the work was to evaluate the quality of eggs sold in traditional stores and in the self-service regime of the Miraflores district. A total of 248 eggs were analyzed. Of which 124 came from traditional shops (stores, market) and 124 eggs from shops under self-service (hypermarket, supermarkets). External characteristics such as cleanliness and integrity, shell thickness, weight and egg size were evaluated. Also, internal characteristics such as the diameter and color of the yolk, the consistency of the white, the presence of spots (meat or blood) in the yolk and white, freshness of the egg. In traditional stores, eggs were sold per kilo, dirtier $(24,19)$ and with more than 17 days of storage. In self-services, eggs were packed in a tray $(100 \%)$, were cleaner $(98,39 \%)$ and with fewer days of storage $(<12$ days). In both types of shops, eggs with spots of meat and / or blood were observed in the white, yolk or both parts of the egg. It was concluded that traditional shops sell lower quality eggs compared to self-services.

Keywords: Eggshell, quality control, yolk, white.

1. Doctora en educación. Jefa de la Unidad de Investigación de la Facultad de Ciencias Agropecuarias. Universidad Alas Peruanas. Email: p_shiroma_t@outlook.com 


\section{INTRODUCCION}

La calidad puede ser definida como las propiedades inherentes de un producto (Coutts \& Graham.,2007; Godínez et al.,1984). Algunos factores que pueden afectar la calidad del huevo son la línea genética, la edad de la gallina, el tiempo transcurrido luego de la ovoposición (Estrada et al., 2010), las condiciones (Jones \& Musgrove., 2005, Oliveira \& Silva., 2000) y el tiempo de almacenamiento (Silverside \& Villenueve., 1994).

Diversas técnicas de laboratorio se han desarrollado para evaluar la calidad del huevo en gallinas de estirpe comercial (Juárez-Caratachea et al.,2011).

Las características externas e internas pueden ser valoradas de manera subjetiva y expresadas de manera cuantitativa (Jaramillo et al.,2018). Los aspectos externos que se evalúan son el peso, la forma y el color del huevo, el grosor, la densidad, el peso, la textura, la limpieza e integridad de la cáscara.

Asimismo, de manera interna, se considera a la frescura, el color de la yema, la presencia de manchas de carne, sangre en la clara o yema, la calidad de la yema y el albumen y a través de análisis microbiológicos (presencia de salmonella) y fisicoquímicos (Juárez-Caratachea et al.,2011; Duman et al., 2016; Jaramillo et al.,2018).

La calidad es considerada como un factor fundamental en la aceptación o el rechazo por parte del consumidor. Por ello, se emplean diversos parámetros con la única finalidad de presentar un producto altamente confiable para los consumidores (Hernández et al., 2013). El objetivo del trabajo fue evaluar la calidad de los huevos expendidos en los comercios tradicionales y autoservicios, localizados en el distrito de Miraflores.

\section{MATERIALES Y MÉTODOS}

Se realizó un muestreo de 248 huevos pardos sin refrigerar en comercios ubicados en el distrito de Miraflores. De los cuales 124 procedían de comercios tradicionales (tiendas y el mercado distrital) y 124 huevos de los comercios en régimen de autoservicio (supermercados, hipermercados).

En relación a la calidad interna, se evaluó la limpieza (huevos con materia fecal, con tierra y sangre) e integridad de la cáscara y defectos de la cáscara a través de la observación, el peso del huevo con una balanza digital, el diámetro polar (longitudinal) y ecuatorial con un vernier y el grosor de la cáscara $(\mathrm{mm})$ utilizando un micrómetro. Por otro lado, para estimar la forma del huevo (índice morfológico) se utilizó la fórmula $\mathrm{IF}=$ diámetro ecuatorial / diámetro polar x 100 .

Las mediciones internas comprendieron: diámetro de la yema con la utilización de un vernier, la pigmentación o color de la yema con la escala colorimétrica de roche (1-15), la consistencia del albumen y la presencia de manchas o inclusiones en el interior del huevo a través de la observación.

Se utilizó la estadística descriptiva para el cálculo de la media aritmética y medidas de dispersión (desviación estándar, coeficiente de variación). Asimismo, se construyó una base de datos en el programa Excel a fin de realizar el análisis estadístico con el programa SPSS 22.

\section{RESULTADOS}

En el análisis de los resultados, se observaron diferencias en algunos atributos de la calidad externa del huevo según el tipo de comercio. Los autoservicios expenden huevos envasados con maple (100\%) en comparación con los comercios tradicionales (0\%).

Los comercios tradicionales vendían huevos de mayor peso $(62,07 \mathrm{~g})$. Pero más heterogéneos en comparación con los autoservicios. No obstante, el grosor $(0,43)$, el tamaño (extra grande) y la forma (globosa o redondeada) fue similar en ambos tipos de comercios (Tabla 1). 
Tabla $N^{\circ} 1$. Características externas del huevo según la forma comercial.

\begin{tabular}{ccccc} 
Características & \multicolumn{2}{c}{ Comercios tradicionales } & Autoservicios & \\
& Media $\pm \mathrm{DE}$ & CV & Media \pm DE & CV \\
Peso del huevo $(\mathrm{g})$ & $62,07 \pm 4,73$ & 7,62 & $61,60 \pm 4,41$ & 7,15 \\
Longitud del huevo $(\mathrm{cm})$ & $5,65 \pm 0,23$ & 4,07 & $5,65 \pm 0,19$ & 3,36 \\
Altura del huevo $(\mathrm{cm})$ & $4,38 \pm 0,15$ & 3,42 & $4,33 \pm 0,13$ & 3,00 \\
Índice morfológico $(\%)$ & $77,84 \pm 3,66$ & 4,70 & $77,3 \pm 2,74$ & 3,54 \\
Grosor de la cáscara $(\mathrm{mm})$ & $0,43 \pm 0,03$ & 6,68 & $0,43 \pm 0,03$ & 6,51
\end{tabular}

La calidad interna de los huevos comercializados en el autoservicio fue mejor con respecto a los comercios tradicionales. En los comercios tradicionales, el 59\% de los huevos vendidos tenían entre 17 a 21 días de almacenamiento, mientras que el 88\% de los huevos en los autoservicios tenían menos de 12 días de almacenamiento. En la tabla 2, se observa los atributos de calidad interna según el tipo de comercio. El diámetro de la yema fue menor y más homogéneo en los autoservicios. Sin embargo, el rango del color de la yema de los huevos comercializados en autoservicios fue más amplio (4-11), en comparación con los comercios tradicionales (3-8).

Tabla N². Características internas del huevo según la forma comercial

\begin{tabular}{ccccc} 
Características & \multicolumn{2}{c}{ Comercios tradicionales } & \multicolumn{2}{c}{ Autoservicios } \\
& Media \pm DE & CV & Media \pm DE & CV \\
Diámetro de la yema & $4,31 \pm 0,39$ & 9,04 & $4,23 \pm 0,20$ & 4,70 \\
Pigmentación de la yema & $5,74 \pm 1,29$ & 22,47 & $6,37 \pm 1,87$ & 29,35
\end{tabular}

La calidad interna de los huevos comercializados en el autoservicio fue mejor con respecto a los comercios tradicionales. En los comercios tradicionales, el 59\% de los huevos vendidos tenían entre 17 a 21 días de almacenamiento, mientras que el $88 \%$ de los huevos en los autoservicios tenían menos de 12 días de almacenamiento. En la tabla 2, se observa los atributos de calidad interna según el tipo de comercio. El diámetro de la yema fue menor y más homogéneo en los autoservicios. Sin embargo, el rango del color de la yema de los huevos comercializados en autoservicios fue más amplio (4-11), en comparación con los comercios tradicionales (3-8).

Tabla $N^{\circ}$. Defectos del huevo comercializado según la forma comercial.

$\begin{array}{ccccc}\text { Características } & \text { Comercio tradicional } & \text { Autoservicio } & \\ & \mathbf{n} & \% & \mathbf{n} & \% \\ \text { Cáscara sucia } & 30 & 24,19 & 2 & 1,61 \\ \text { Huevos rotos } & 2 & 1,61 & 2 & 1,61 \\ \text { Cáscara defectuosa } & 4 & 3,23 & 0 & 0 \\ \text { Claras acuosas } & 120 & 96,77 & 120 & 96,77 \\ \text { Manchas en la clara } & 38 & 30,64 & 58 & 46,77 \\ \text { Manchas en la yema } & 20 & 16,12 & 8 & 6,45 \\ \text { Manchas en la clara y yema } & 21 & 16,93 & 16 & 12,90\end{array}$




\section{DISCUSIÓN}

El proceso de producción y comercialización desde la granja hasta el consumidor implica una serie de operaciones que pueden alterar su calidad (España., 2014). Los huevos que eran comercializados en los comercios tradicionales y autoservicios tenían una baja calidad interna, debido a que son mantenidos a temperatura ambiental hasta el momento que llega al consumidor. La temperatura, el tiempo de almacenamiento pueden influenciar en la frescura del huevo (Carrazzoni de Meneses et al., 2012). Inmediatamente después de la puesta, comienza un proceso de deterioro irreversible que ni siquiera el almacenamiento en condiciones óptimas puede detener, sin embargo, mientras más rápido se refrigeren los huevos se preserva su calidad (Estrada et al.,2010).

En tal sentido, es importante que se preste atención a los problemas de conservación y comercialización de los huevos para mantener la calidad del huevo (Hanusova et al., 2015, Bozrut \& Tekerli., 2009).

En los comercios tradicionales se expendían huevos más sucios, heterogéneos en peso y de mayor tamaño en comparación con los autoservicios. Los defectos en la calidad del huevo son considerados como desviaciones de los estándares de la calidad interna y externa que afectan la calidad. La calidad exterior del huevo se juzga en función de la densidad, textura, color, la forma, la firmeza, grosor, limpieza de la cáscara y el peso del huevo (Kingori., 2012).

Asimismo, en esta investigación, no se observaron diferencias marcadas en los atributos de la calidad interna del huevo (presencia de manchas, consistencia del albumen), a pesar que en los autoservicios los huevos estaban más frescos. Desde el punto de vista del consumidor, la calidad interna se valora por la limpieza y viscosidad del albumen o clara, tamaño de la cámara de aire, forma de la yema (Kingori.,2012), color y dimensión de la yema. Estas características suelen ser consideradas por su valor biológico, las particu- laridades dietéticas, el valor comercial y genético (Godínez et al., 1984).

Por lo tanto, es importante determinar la calidad de huevos para evaluar el deterioro que estos sufren con el tiempo, en relación a las condiciones de almacenamiento; así como también, es útil para describir las diferencias en huevos frescos provenientes de ponedoras genéticamente distintas, o cuando son sometidas a diferentes condiciones medio ambientales y nutricionales $(\mathrm{Na}$ varro.,2000; Silverside \& Villeneuve., 1994).

\section{CONCLUSIONES}

A partir del análisis de los datos del estudio, se pudo concluir que los comercios tradicionales no hacen un control de calidad de los huevos comercializados, antes de llegar al consumidor. Debido a que expenden con mayor frecuencia huevos con cascara sucia y con menor porcentaje de frescura en comparación con los autoservicios. Por ello, es importante que el consumidor tome conciencia sobre las implicancias que tiene en la salud pública, consumir huevos con una pobre calidad higiénica.

\section{BIBLIOGRAFÍA}

1. Bozkurt, Z., Tekerli, M (2009). The effect of hen age, genotype, period and temperature of storage on egg quality. Kafkas Univ Vet Fak Derg. 15 (4): 517-524.

2. Carrazzoni de Menezes, P., Rodrigues de Lima, P., Pinto de Mediros, J., Ketruy de Oliveria, W., Evencio-Neto, J (2012). Egg quality of laying hens in different conditions of storage, ages and housing densities. R. Bras. Zootec., 41(9): 2064-2069.

3. Coutts, Jeffrey., Wilson, G. (2007). Manual Práctico de calidad del huevo. F Hoffman La Roche, España, Pág. 2254.

4. Duman, M., Şekeroğlu, A., Yıldırım, A., Eleroğlu, h., Camc1, Ö (2016). Relation between egg shape index and egg quality characteristics. Europ.Poult.Sci., 80.2016. DOI: 10.1399/eps.2016.117.

5. España, C (2014). Evaluación de la calidad del huevo de codorniz (Coturnix coturnix japonica) comercializado en el municipio de Pasto, departamento de Nariño. [Tesis título de zootecnista]. Colombia: Universidad de Nariño. 
6. Estrada, M., Galeano, L., Herrera, M., Restrepo, L (2010). Efecto de la temperatura y el volteo durante el almacenamiento sobre calidad del huevo comercial. Rev Colomb Cienc Pecu. 23:183-190

7. Godínez, O., Salcedo, EI., Fonseca, L. (1984). Evaluación de la calidad interna y externa del huevo de varias razas de gallinas. Rev. Cubana de Cienc. Avic,11 (1-2): 49-60.

8. Hanusova E, Hrnčár, C., Oravcová, M (2015). Effect of breed on some parameters of egg quality in laying hens. Acta fytotechn. zootechn., 18, (1): 20-24

9. Hernández-Bautista, J., Pérez -León, I., Gonzales-Martínez, A., Villegas-Aparicio, Y., Rodríguez-Ortiz G, et al (2013). Calidad del huevo de cuatro líneas genéticas de gallinas en clima cálido. Revista Mexicana de Ciencias Agrícolas Pub. Esp. 6 (14 de agosto - 26 de septiembre):1107-1118

10. Jaramillo, A., Mogica J, Caro E, Sosa, J (2018). Evaluación de la calidad de gallina en dos sistemas de alojamiento-piso convencional con suplementación de sauco (Sambucus nigra) y pastoreo con Kikuyo (Pennisetum clandestinum) en la sabana de Bogotá. Revista Siembra CBA. 2 (1): 59-77.

11. Jones, D., Musgrove, M (2005). Effects of extended storage on egg quality factors. Poultry Science. 84:1774-1777.

12. Juárez-Caratachea A, Gutiérrez-Vázquez E, Pérez-Sánchez RE, Román-Bravo R, Ortiz-Rodríguez R (2011). Evaluación física de la calidad externa e interna del huevo de pavas nativas (Melleagris gallipavo g.) Revista Científica. 21 (6): $524-532$.

13. King' ori, A.M (2012). Poultry egg external characteristics: Egg weight, shape and shell colour. Research Journal of Poultry Sciences 5(2): 14-17.

14. Navarro, M (2000). Estudio de factores de la calidad del huevo en ponedoras Isa Brown y Shaver Cross sometidas a diferentes dosis de Esparteína y alcaloides totales de lupino. [Tesis de grado]. Santiago de Chile: Universidad Austral de Chile.

15. Oliveira, DD., Silva, EM (2000). Salmonella em ovos comercias: ocorrência, condições de armazenamento e desinfecção da casca. Arq. Bras. Med. Vet. Zootec. 52 (6): 655-661.

16. Silversides, FG., Villeneuve, P (1994). Is the Haugh unit correction for egg weight valid for eggs stored at room temperature? Poult Sci, 73, 50-55. 